\title{
Effects of $\alpha$-keto- $\delta$-guanidinovaleric acid on inhibitory amino acid responses on mouse neurons in cell culture
}

\author{
P.P. De Deyn ${ }^{1}$, B. Marescau ${ }^{2}$ and R.L. Macdonald ${ }^{1}$ \\ ${ }^{\prime}$ Department of Ncurology, University of Michigan Medical Center, Ann Arbor, MI 48104 (U.S A ) and '2 Laboratory of \\ Neurochemistry, Born-Bunge Foundation and Laboratory of Neuropharmacology, Antwerp (Belgium)
}

(Accepted 3 November 1987)

Key words: $a$-Keto- $\delta$-guanidinovaleric acid; Convulsant; Hyperargınınemia, $\gamma$-Amınobutyric acid-response; Glycıne-response; Epıleptogenicıry; Prımary dissociated neuronal cell culture

\begin{abstract}
The experimentally proven convulsant $\alpha$-keto- $\delta$-guanıdinovaleric acid ( $\alpha$-K- $\delta$-GVA) was applied to mouse spinal cord neurons in primary dissuciated cell culture to assess its effects on postsynaptic $\gamma$-aminobutyric acid (GABA)- and glycine (GLY)-responses. Intracelly' ar microelectrode recording techniques were used. $\alpha-K-\delta$-GVA reversıbly inhıbited both GABA- and GLY-respones in a concentration-dependent manner. The effect of $\alpha-K-\delta$-GVA on GABA-responses was not antagonized by co-application of the benzodıazepine receptor antagonist CGS 9896 The results suggest that $a$-K- $\delta$-GVA inhibited responses to the inhibitory neurotransmitters GABA and GLY by blocking the chloride channel. This action might underlie the convulsant effect of this compound in rabbit. The possible pathophysiological importance of $a-\mathrm{K}-\delta$-GVA in hyperarginınemıc patients is discussed.
\end{abstract}

\section{INTRODUCTION}

$\alpha$-Keto- $\delta$-guanidinovaleric acid ( $\alpha$-K- $\delta$-GVA), a monosubstituted guanidino compound, has been identified in urine, serum and cerebrospinal fluid of hyperargininemic patients ${ }^{14,15,17}$. Hyperargininemia is an inborn error of metabolism characterized by a deficiency of arginase, the last enzyme of the urea cycle, which converts arginine to urea and ornithine. The first clinical and biochemical descriptions were published in $1969^{34}$ and $1970^{35,36}$. Since then, 18 other

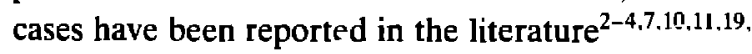
$20.24,25,28.31 .3237,38$. The disease is autosomal recessive. Patients with this disorder show similar clinical symptoms: Irritability, vomiting, a progressive pyramidal spasticity and epilepsy. In addition, some patients have an episodıc hyperammonemia and mental retardation.

The causative factors of the neurological symptomatology are not clear. Possible factors could be the disturbance of ammonia metabolism or the accu- mulation of arginine and its catabolites, the guanidino compounds. The presence of normal or only slightly elevated plasma ammonium levels in several patients ${ }^{4,19,25,31}$ casts doubt on the former hypothesis. However, several guanidino compounds, metabolites of arginine, consistently accumulate in biological fluids of hyperargininemic patients ${ }^{14,15,17}, \alpha-\mathrm{K}-\delta$ GVA, one of these guanidino compounds, was demonstrated to be a convulsant in rabbit. After topical application of $\alpha$-K- $\delta$-GVA on the sensory motor cortex, tonic-clonic seizures were evoked and epileptiform discharges were recorded on the electroencephalogram $^{16}$. The experimentally observed epileptogenicity of this keto analogue of arginine might contribute to the epileptic symptomatology observed in hyperargininemic patients.

Several convulsants have been shown previously to inhıbit responses to iontophoretically applied GABA on mammalian spinal cord neurons grown in cell culture ${ }^{13}$. In an attempt to determine the mechanisms through which $\alpha$-K- $\delta$-GVA might produce sei-

Correspondence: R L Macdonald, Neuroscience Laboratory Buılding, 1103 East Huron, Ann Arbur, MI 48104, U S A 
zures, we studied its influence on responses evoked by iontophoretically applied GABA and GLY on mouse spinal cord neurons in primary dissociated cell culture. Intracellular microelectrode recording techniques were used.

\section{MATERIALS AND METHODS}

\section{Primary dissociated cell culture}

Cultures of spinal cord neurons were prepared from dissected spinal cords and attached dorsal root ganglia from 12-14-day-old fetal mice as described previously ${ }^{27}$. The tissue was minced and then mechanically dissociated by trituration in $\mathrm{Ca}^{2+}$ - and $\mathrm{Mg}^{2+}$ free balanced salt solution to a suspension of single cells and smali clumps. The dissociated cells were suspended in culture medium [ $90 \%$ Eagle's minimal essential medium supplemented with $5.5 \mathrm{~g}$ of glucose and $1.5 \mathrm{~g}$ of $\mathrm{NaHCO}_{3} / 5 \%$ heat-inactivated horse serum and 5\% Nu-Serum II (Collaborative Research Inc.), $325 \mathrm{mOsm}$ ] and then plated on sterile collagencoated 35-mm dishes. The cultures were maintained in an incubator with an atmosphere of $93 \%$ room air and $7 \% \mathrm{CO}_{2}$ at $35^{\circ} \mathrm{C}$. The bicarbonate $/ \mathrm{CO}_{2}$ buffer maintained $\mathrm{pH}$ at 7.4. 5-Fluoro-2'-deoxyuridine was added to the cultures on days 6-8 to suppress the growth of rapidly dividing non-neuronal cells. Medium was changed twice weekly. Cultures were maintained for 4-9 weeks before electrophysiological experiments.

\section{Experimental procedures}

Solutions. All recordings were made in a Dulbecco's phosphate-buffered saline (DPBS) after removal of growth medium. The DPBS, with elevated magnesium ion concentration in order to suppress spontaneous activity, contaned (1n mM): $\mathrm{NaCl} 137$, $\mathrm{Na}_{2} \mathrm{HPO}_{4} 8.06, \mathrm{KCl} 2.68, \mathrm{KH}_{2} \mathrm{PO}_{4} \perp 47, \mathrm{CaCl}_{2} 1$, $\mathrm{MgCl}_{2} 10$ and glucose 5.6 (pH 7.3-7.4). Heavy paraffin oil was applied to the surface of the bathing solution to retard evaporation.

Solutions of $\alpha-\mathrm{K}-\delta$-GVA were always prepared on the day of the experiment in the following manner. Dry enzymatically synthesized $\alpha-K-\delta$-GVA was dis. solved in DPBS to form $1 \mathrm{M}$ stock solution Alie sots were removed and diluted in DPBS to give concentrations between $1 \mathrm{nM}$ and $100 \mathrm{mM}$.

Experimental apparatus. For experiments, the cul- ture dish containing the bathing solution was placed on a stage heated by a Pellitier device with temperature regulated at $34-35^{\circ} \mathrm{C}$. The stage was mounted on a Leitz inverted microscope fitted with phase-contrast optics to facilitate micropipette placement (using Leitz micromanipulators) and to penetrate cells under direct visual control.

Electrophysiological recordings. Intracellular recordings were made from the somata of spinal cord neurons ( $>20 \mu \mathrm{m})$ using glass micropipettes (20-25 $\mathrm{M} \Omega$ ) filled with $3 \mathrm{M} \mathrm{KCl}$. Use of an active bridge circuit (Dagan 8100 or W-P Instruments M707) allowed simultaneous recording of membrane potential and injection of current (for steady-state polarization or periodic stimulation) using a single micropipette. The preamplifier output was led to a '-channel polygraph (Gould 2600S) for continuous recording.

$G A B A$ - and GLY-responses. GABA $(0.5 \mathrm{M}, \mathrm{pH}$ 3.4) and GLY (0.5 M, pH 3.0) were applied iontophoretically using 500-ms duration rectangular current pulses at 5-s intervals. lontophoretic pipettes were positioned to within $2 \mu \mathrm{m}$ of neuronal somata. The use of $3 \mathrm{M} \mathrm{KCl-filled} \mathrm{micropipettes} \mathrm{shifted} \mathrm{th-}$ chloride equilibrium potential from about $-65 \mathrm{~m}^{\top}: 0$ about $-20 \mathrm{mV}$. Under these conditions, an inc :ase of chloride conductance resulted in an outward chloride current ${ }^{5}$, giving depolanzing GABA- and GLYresponses $^{5.22}$. Responses of about $10-15 \mathrm{mV}$ in amplitude were evoked following membrane hyperpolarization $(-70$ to $-90 \mathrm{mV})$ to avoid saturation at or near the reversal potential and to obtain a large transmembrane chloride ion gradient. Effects on GABA- and GLY-responses were accepted only if the responses returned to control amplitude within 5 min of removal of the $\alpha-\mathrm{K}-\delta$-GVA-containing micropipette.

Drug application For evaluation of $\alpha$-K- $\delta$-GVA effects on GABA- and GLY-responses, $\alpha$-K- $\delta$-GVA was applied by miniperfusion. A blunt-tipped (5-10 $\mu \mathrm{m})$ micropipette filled with the test solution was positioned $15-30 \mu \mathrm{m}$ from the soma of the cell under study. The open end of the miniperfusion pipette was connected to a pressure regulator, set between 0.4 and 0.8 pounds per square inch ( $\mathrm{psi}$ ), by tight-fitting polyethylene tubing. Piessure pulse duration, regulated by a voltage-activated 3-way valve, was $10 \mathrm{~s}$. Under these conditions, miniperfusion produced no artifacts, and application of control solution (DPBS 
alone) was virtually free of effects. The concentrations reported in this study were those contained in the miniperfusion micropipettes. While it is possible that there was some reduction in the concentration of drug at the neuronal surface due to dilution in the surrounding medium, increasing durations of application or altering the position of the micropipette did not increase the effects of the drugs. Thus, while there might be some small inaccuracy in the drug concentrations, the reported concentrations are likely to be quite close to those existing at the surface of the neuron. For assessment of the possible antagonist effect of the pyrazoloquinoline CGS 9896 (a pure benzodiazepine receptor antagonist ${ }^{6}$ ) on $a-K-\delta$-GVA-induced changes of GABA-responses, CGS 9896 (1 $\mu \mathrm{M}$ ) was applicủ by diffusion from large-tipped (10$20 \mu \mathrm{m})$ micropipettes before application by miniperfusion of $\alpha-\mathrm{K}-\delta$-GVA. As control, DPBS alone applied by diffusion was without effect in this paradigm. The miniperfusion pipettes and recording micropipettes were held by Leitz micromanipulators. To decrease leakage of drugs into the bathing medium, the tips of the miniperfusion pipettes were kept in the oil phase between drug application trials. They were lowered into the aqueous phase only when drug application was desired.

Drugs. CGS 9896 (2-(4-chlorophenyl)-2,5-dihydropyrazolo(4,3-C)quinoline-3(3-H)-one) was provided by Ciba-Geigy-Corp., Summit, New Jersey, U.S.A. GABA and GLY were purchased from Sigma Chemical Company, St. Lous, Missourı, U.S.A.

$a-K-\delta$-GVA was synthesized enzymatically by a modification of the method of Meister ${ }^{18}$. Arginine (1000 mg), free-base, and $355 \mathrm{mg}$ boric acıd were dissolved in $50 \mathrm{ml}$ water. L-amino acid oxidase (17.5 U) (Sigma A5147; $0.35 \mathrm{U} / \mathrm{mg}$, solid one unit will oxidatively deaminate $1.0 \mu \mathrm{mol}$ of L-phenyl-alanine/min at $\mathrm{pH} 6.5$ at $37{ }^{\circ} \mathrm{C}$ ) were added to this solution. The $\mathrm{H}_{2} \mathrm{O}_{2}$ formed was decomposed by adding $10^{n}, 000$ units catalase (Aidrıch; 120,000 units/ml solution). The $\mathrm{pH}$ of the solution, originally at $\mathrm{pH}=9.2$, was brought to a $\mathrm{pH}$ of 7.6 with approximately $6 \mathrm{ml} 1 \mathrm{~N}$ $\mathrm{HCl}$. The vessel contaning this solution was placed in a waterbath at $37^{\circ} \mathrm{C}$. An $\mathrm{O}_{2}$ stream was continuously bubbled through the solution. The enzymatic oxidative deamination occurred over a 24-h period. Every $6 \mathrm{~h}, 17.5 \mathrm{U}$ of L-amino acid oxidase and 108,000
$\mathrm{U}$ of catalase, were added to the solution and the $\mathrm{pH}$ was also controlled. The solution was deproteinized by dialysis against water. Boric acid was eliminated by passing the deproteinized solution over a cation exchange column ( $\mathrm{H}^{+}$form), and the resin was washed with water. $\alpha-\mathrm{K}-\delta$-GVA was eluted from the column by passing $0.5 \mathrm{~N} \mathrm{NH}_{4} \mathrm{OH}$ solution through the column. The eluate was concentrated by evaporation with a rotavapor under vacuum to about $15 \mathrm{ml}$. Out of this solution a first crystallization was performed. A white powder was obtained. A second crystallization from hot water gave well-formed crystals. The purity of the synthesized compound was controlled by liquid chromatography and nuclear magnetic resonance.

Algebraic and statistical methods. At all applied concentrations, mean values and standard deviations were calculated for the effects on GABA- and GLYresponses. The effects were expressed as percentage decrease of GABA- or GLY-responses. The statistical significance of differences between control and drug groups was calculated using the two-tailed Student's $t$-test; $P<0.05$ was considered statistically significant.

\section{RESULTS}

Miniperfusion of $\alpha$-K- $\delta$-GVA did not alter resting membrane potential or conductance. Miniperfusion of DPBS alone $(n=10)$ gave non-significant enhancement $(0.8 \pm 1.9 \%)$ of GABA- and GLY-re-

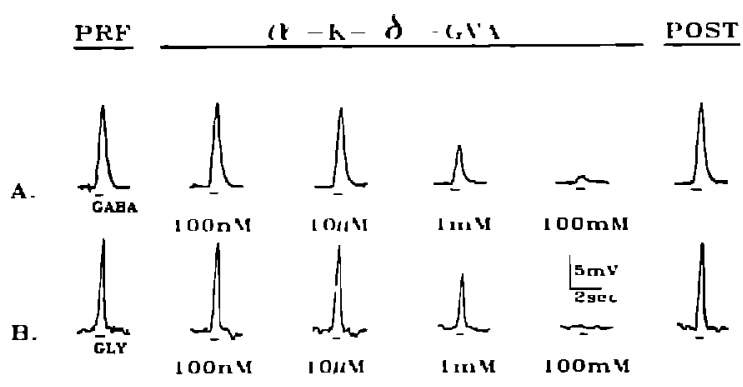

Fig 1 Reversible, concentration-dependen, effects of $a-K-\delta$ GVA on GABA-respionses (A) and on GLY-responses (B) on spinal cord neurons Row $A$ and $B$ show respones obtained on one cell. PRE shows stable GABA- and GLY-responses before drug application. The 4 middle responses show the effect of the miniperfused drug. GABA- and GLY-responses returned to control values (POST) with 2 min following removal of the $a$ K- $d$-GVA containing micropipette. Iontophoretic application of GABA or GLY is indicated with a dash. 


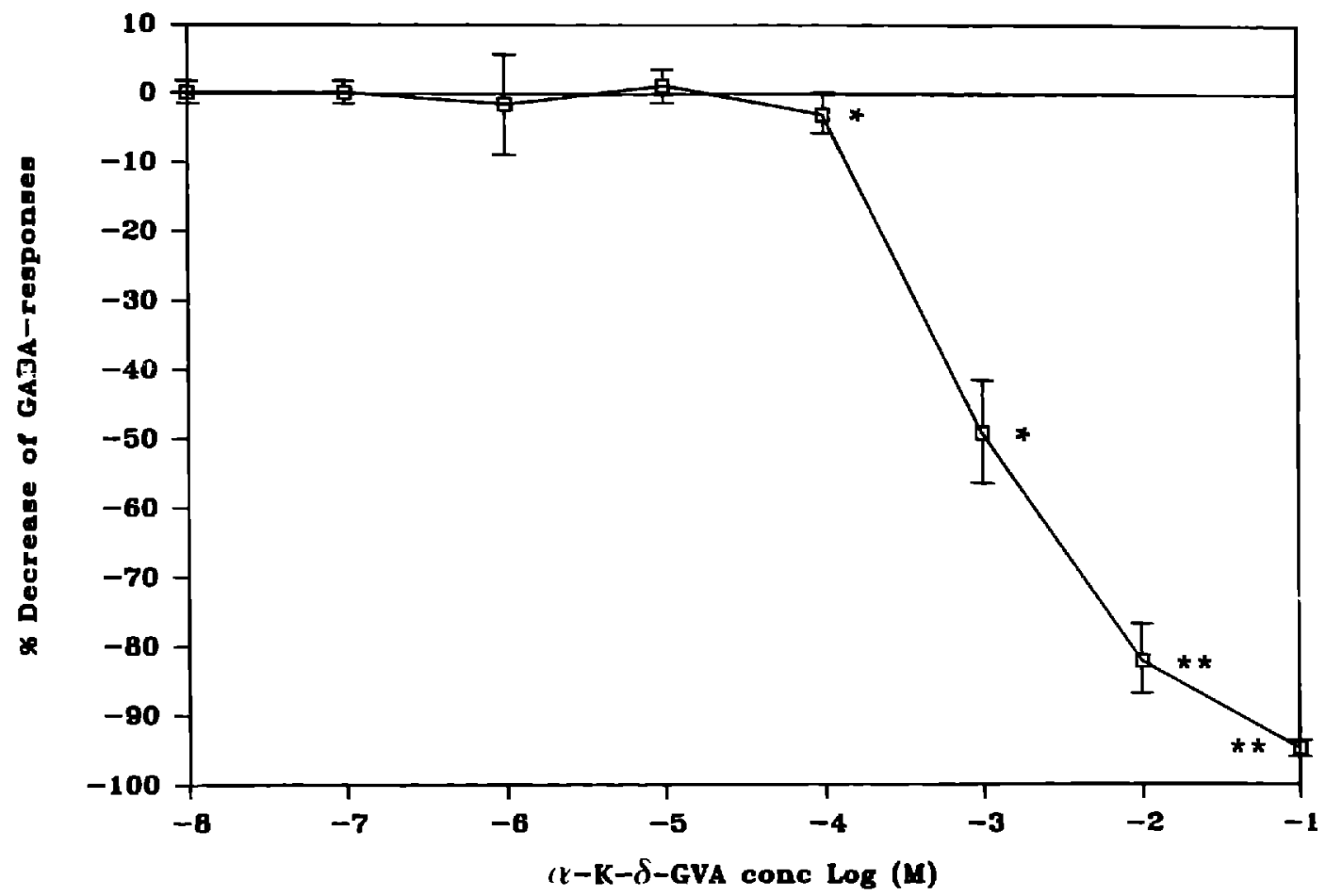

Fig. 2. Concentration-dependent decrease of GABA-responses in spinal cord neurons by $a-K-\delta$-GVA. Effects are expressed in percentage decrease of the original GABA-response. Data shown are means and standard deviations. Three to six cells have been studied for each concentration tested. " $P<0.01,{ }^{* *} P<0.001$ from control GABA-response. $\alpha$-K- $\delta$-GVA concentrations on the abscissa are logarithm molar.

sponses. Reversible effects of $\alpha-\mathrm{K}-\delta$-GVA on GABA- and GLY-responses are shown in Fig. 1. $\alpha$ K- $\delta$-GVA reversibly decreased GABA-responses (Fig. 1A) as well as GLY-responses (Fig. 1B). The effects of $c$-K- $\delta$-GVA on GABA-responses (Fig. 1A) and GLY-responses (Fig. 1B) were concentrationdependent. The concentration dependency of the effect of $\alpha$-K- $\delta$-GVA on GABA-responses is further illustrated in Fig. 2. $A$ significant $3.6 \pm 2.9 \%$ reduction $(P<0.01)$ was obtained at $100 \mu \mathrm{M}$ and a $94.4 \pm$ $1.4 \%$ decrease was obtained at $100 \mathrm{mM}(P<$ 0.0001). Non-significant etfects were observed at concentrations ranging from $10 \mathrm{nM}$ to $10 \mu \mathrm{M}$. The concentration-dependency of the effect of $\alpha-\mathrm{K}-\delta$ GVA on GLY-responses is shown in Fig. 3. At 100 $\mu \mathrm{M}$, a non-significant $2.5 \pm 5.5 \%$ decrease of GLYresponses was observed. A significant $21.2 \pm 8.6 \%$ reduction $(P<0.01)$ was obtained at $1 \mathrm{mM}$ and a $99.5 \pm 1.0 \%$ decrease $(P<0.0001)$ was seen at 100 $\mathrm{mM}$.
Application of CGS $9896(1 \mu \mathrm{M})$ by diffusion, before application of $a-\mathrm{K}-\delta$-GVA $(10 \mathrm{mM})$ by ininiperfusion, did not significantly influence the effect of $a$ K- $\delta$-GVA on GABA-responses (Table I).

\section{DISCUSSION}

Several convulsants have been shown previously

\section{TABLE I}

CGS 9896, a benzodıüzepine receptor antagonist, did not influence the effect of $a-K-\delta-G V A$ on $G A B A$-responses on mouse spinal cord neurons

\begin{tabular}{lll}
\hline & $\begin{array}{l}\text { Number of } \\
\text { neurons } \\
\text { studied }\end{array}$ & $\begin{array}{l}\text { GABA-responses } \\
\text { \% of control } \\
\text { (mean } \pm \text { S.D ) }\end{array}$ \\
\hline CGS 9896 1 $\mu \mathrm{M}$ & 9 & $100.2 \pm 4.9$ \\
$\begin{array}{l}\alpha-\mathrm{K}-\delta \text {-GVA } 10 \mathrm{mM} \\
a-\mathrm{K}-\delta \text {-GVA } 10 \mathrm{mM}+\end{array}$ & 5 & $18.0 \pm 5.2$ \\
CGS 9896 $1 \mu \mathrm{M}$ & 3 & $185 \pm 10.0$ \\
\hline
\end{tabular}




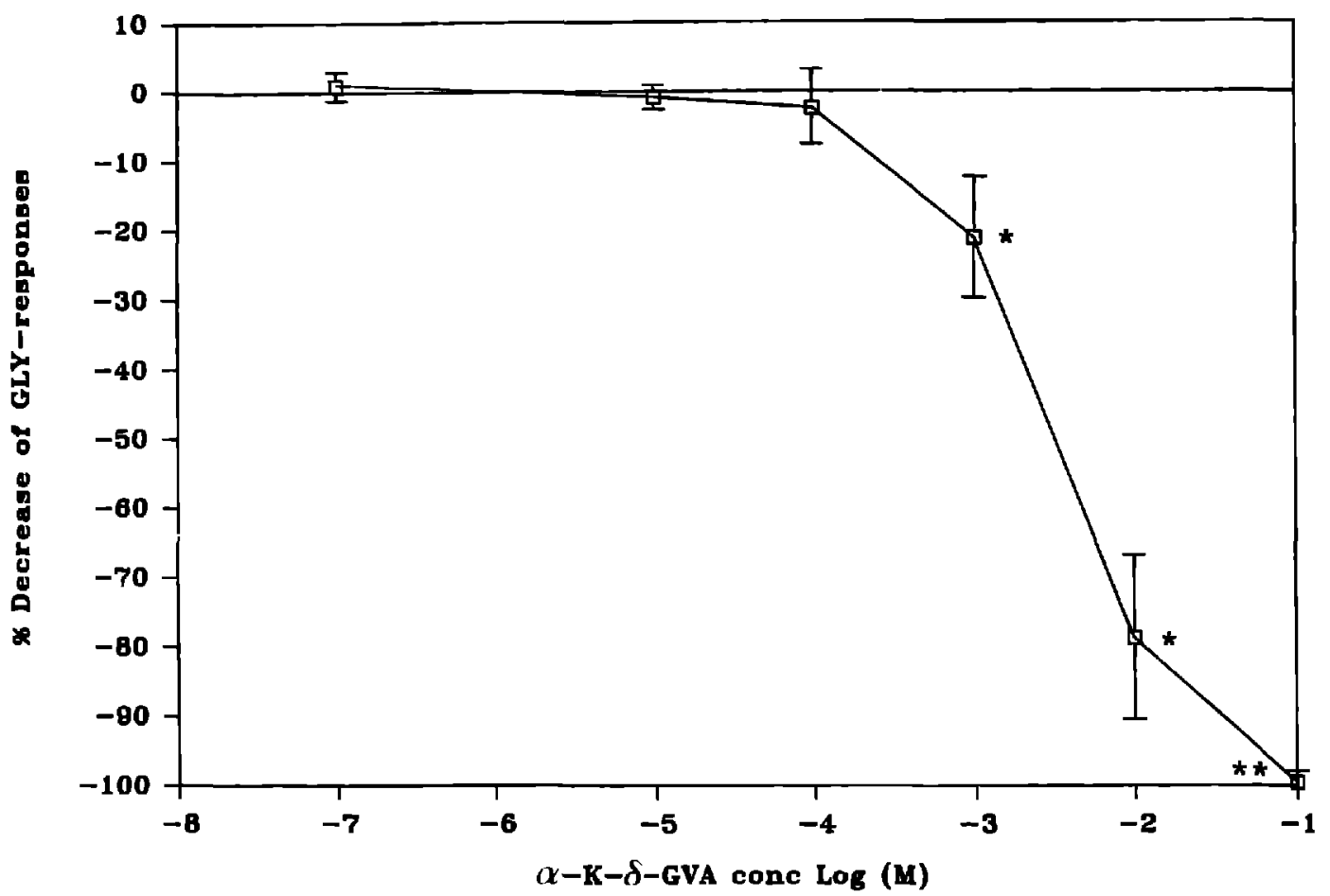

Fig. 3. Concentration-dependent decrease of GLY-responses on spinal cord neurons by $a-K-\delta$-GVA. Effects are expressed in percentage decrease of the original GLY-response. Data shown are means and standard deviations. Three to six cells have been studied for each concentration. ${ }^{*} P<0.01,{ }^{* *} P<0.001$ from control GLY-responses. $\alpha$-K- $\delta$-GVA concentrations on the abscissa are logarithm molar.

tc inhibit GABAergic neurotransmission ${ }^{12,23,29,30}$ through interaction with a supramolecular receptor complex $^{33}$. This protein complex, located on the postsynaptic membrane, consists of a functionally coupled benzodiazepine receptor, GABA-receptor and chloride channel. $A$ variety of convulsants reduced responses to iontophoretically applied GABA on mouse neurons in cell culture. DMCM, a convulsant $\beta$-carboline, reduced GABA-responses through an interaction with the benzodiazepine receptor ${ }^{9,30}$. Another benzodiazepine receptor ligand with proconvulsant effect, CGS 8216, also inhibited GABAresponses ${ }^{6}$. Furthermore, the convulsants bicuculline, picrotoxin, pentylenetetrazol, and penicillin were previously reported to be selective antagonists of GABA-mediated postsynaptic inhibition in cultured mammalian neurons ${ }^{12,23,29}$.

In this study, we evaluated the effects of $\alpha-\mathrm{K}-\delta$ GVA (an experimentally proven convulsant ${ }^{16}$ ) $\mathrm{cn}$ responses to iontophoretically applied inhibitory neurotransmitters (GABA and GLY) on mouse neurons in primary dissociated cell culture.

Our findings demonstrated that $\alpha-\mathrm{K}-\delta$-GVA reversibly decreased GABA- and GLY-responses on mouse spinal cord neurons in culture in a concentration-dependent manner. The results furthermore indicated that $\alpha-K-\delta$-GVA did not exert its effects through interaction with the benzodiazepine receptor. Indeed, CGS 9896, a benzodiazepine receptor antagonist, did not antagonize the inhibitory effect of $\alpha$-K- $\delta$-GVA on GABA-responses. Earlier studies indicated that the inhibitory neurotransmitters GABA and GLY act through different receptors on the surface membranes of these cultured neurons ${ }^{13,21,26}$. Furthermore, activation of chloride condictance has been demonstrated to underlie the GABA- and GLY-receptor-coupled events ${ }^{1}$. Since GABA and GLY exert their effects by activation of chloride conductance through interaction with different receptors, our observations suggest that $\alpha-\mathrm{K}-\delta$-GVA, 
shown here not to be a benzodiazepine receptor ligand, may inhibit inhibitory amino acid-responses by blocking chloride channels.

One must question the pathophysiological importance of the observed inhibitory effects of $a-\mathrm{K}-\delta$ GVA on inhibitory neurotransmitter-responses. Indeed, the $a-K-\delta$-GVA-induced decrease of GABAand GLY-responses was obtained only at concentrations higher than those hitherto found in cerebrospinal fluid of hyperargininemic patients. However, determinations of $a-\mathrm{K}-\delta$-GVA levels have only been performed on cerebrospinal fluid of treated hyperarginınemic patients. Higher levels are to be expected in untreated patients. Moreover, when evaluating the possible neurotoxicity of a given compound, one should take its possible accumulation in brain tissue into account. Finally, different guanidino compounds might have an additive epileptogenic effect. A summative toxic effect has, for example, been demonstrated for other guanidino compounds in a paradigm

\section{REFERENCES}

1 Barker, J L and Ransom, B.R , Amino acid pharmacology of mammalian central neurones grown in tissue culture, $J$. Physiol. (Lond.), 280 (1978) 331-354.

2 Bernar, J., Hanson, R.A., Kern, R., Phoenix, B , Shaw, K.N.F. and Cederbaum, S.D , Arginase deficiency in a 12year-old boy with mild impa:rment of irtellectual function, $J$ Pediatr, 108, No. 3 (1986) 432-435.

3 Cederbaum, S.D , Shaw, K.N.F. and Valente, M., Hyperargininemı, J Pediatr, 90 (1977) 569-573

4 Cederbaum, S.D., Shaw, K.N.V., Spector, E.B , Verity, M A., Snodgrass, P J. and Sugarman, G.I , Hyperarginuremı with arginase deficiency, Pediatr Res., 13 (1979) 827

5 Curtis, D.R , Hòsli, L., Johnston, G.A.R. and Johnston, I.H., The iyperpolarization of spinal motoneurones by glycine and related amino acids, Exp Brain Res, 5 (1968) 235-258.

6 De Deyn, P and Macdonald, R.L., CGS 9896 and ZK 91296, but not CGS 8216 and Ro 15-1788, are pure benzodazepine receptor antagonists on mouse neurons in culture, J. Pharmacol Exp Ther, in press

7 Endres, W., Schaller, R and Shın, Y.S., Diagnosis and ureatment of arginınaemia Characterıstıcs of arginase in human erythrocytes and tissues, J. Inner. Metabol. Dis., 7 (1984) 8 .

8 Giovannettı, S , Cioni, L , Balestri, P.L. and Biagini, M., Evidence that gianıdines and some related compounds cause haemolysis in chronic uremia, Clin. Sci, 34 (1968) 141-148.

9 Jensen, M S and Lambert, J.D.C., The interaction of the $\beta$-carboline derivative DMCM with inhıbitory amino acid responses on cultured mouse neurones, Neurosct Lell , 40 (1983) 175-179. testing autohemolysis ${ }^{8}$.

In conclusion, $\alpha$-K- $\delta$-GVA, a guanidino compound found to be increased in the biological fluids of hyperargininemic patients, inhibited responses to the inhibitory neurotransmitters GABA and GLY on mouse neurons in cell culture. The underlying mechanism is suggested to be the blocking of chloride channels. This effect might explain the in vivo epileptogenicity of this compound in rabbit. The possible pathophysiological importance of this neurotoxin in hyperargininemic patients is still uncertain.

\section{ACKNOWLEDGEMENTS}

The authors wish to thank Ms. Nancy Fox for technical assistance. Financial support was provided through the U.S. Public Health Service (Grant NS 19613), the Rotary Foundation of Rotary International and the Born-Bunge Foundation.

10 Jorda, A., Rubio, V., Portoles, M , Vilas, J. and GarciaPino, J., A new case of arginase deficiency in a spanish male, J. Inher Merabo!. Dis., 9 (1986) 393-397.

11 Kang, S S , Wong, P.W.K. and Milyn, M.A , Hyperargininemia: effect of ornthine and lys:ne supplementation. $J$. Pediatr., 103 (1983) 763-765.

12 Macdonald, R L. and Barker, J.L, Pentylenetetrazol and penicillın are selectıve antagonists of GABA-mediated postsynaptic inhibition in cultured mammalian neurones, Nature (Lond ), 267 (1977) 720-721

13 Macdonald, R.L. and Barker, J.L., Specific antagonısm of GABA-mediated postsynaptic inhibıtion in cultured mammalıan spinal cord neurons: a common mode of convulsant action, Neurology, 28 (1978) 325-330.

14 Marescau, B. and Lowenthal, A., Isolation and identificaton of some guanidino compounds in the urine of patients with hyperargininemia by liquid chromatography, thin-layer chromatography and gas chromatography-mass spectrometry, J. Chromatogr, 224 (1981) 185-195.

15 Marescau, B , Pintens, J. Lowenthal, A., Esmans, E., Luyten, Y., Lemière, G., Domısse, R., Alderweıreldt, F. and Terheggen, H.G., Isolation and identification of 2-oxo-5guanıdinovaleric acid in urine of patients with hyperargininemia by chromatography and gas chromatography/mass spectrometry, J Clin. Chem. Clin Biochem, is (1981) 61-65.

16 Marescau, B , Hıramatsu, M and Morı, A , $a$-Keto- $\delta$-guanidinovaleric acid-induced epileptiform discharges in rabbits, Neurochem. Pathol, 1 (1983) 203-209

17 Marescau, B., Qureshi, I A , De Deyn, P., Letarte, J , Ryba, R. and Lowenthal, A., Guanidino compounds in plasma, urinc and cerebrospinal fluid of hyperargininemic patients during therapy, Clin. Chem Acta, 146 (1985) 21-27 
18 Meister, A., The $a$-keto analogs of arginine, ornithine and lysine, J. Biol. Chem., 206 (1954) 577-583.

19 Michels, V.V. and Beaudet, A.L , Arginase deficiency in multiple tissues in argininema, Clin. Genet., 13 (1978) 61-67.

20 Mizutani. N., Machaca, M., Hayokawa, C., Kato, T , Watanabe, K. and Suzuki, S., Hyperargininemia clinical course and treatment with sodium benzoate and phenylacetic acid, Brain Dev., 5 (1983) 555-563.

21 Nelson, P.G., Ransom, B.R., Henkart, M. and Bullock, P.N., Mouse spinal cord in cell culture. IV. Modulation of inhibitory synaptic function, $J$. Neurophysiol., 40 (1977) 1178-1187.

22 Nishi, S., Minota, S. and Karezmar, A.G., Primary afferent neurons: the ionic niechanism of GABA-mediated depolanzation, Neuropharmacology, 13 (1974) 215-219.

23 Nowak, L.M., Young, A.B. and Macdonald, R.L., GABA and bicuculline actions on mouse spinal cord and cortical Delirons in cell culture, Broin Research, 244 (1982) 155-164.

24 Quereshi, I.A., Letarte, J., Quellet, R., Lehevre, $\mathbf{M}$ and Laberge, $C$., Ammonta metabolism in a family affected by hyperargininemia, Diabetes Metabol., 7 (1981) 5.

25 Quereshi, I.A., Letarte, J , Quellet, R. and Larochelle, J., A new French-Canadian family uffected by hyperargininemia, J. Inher. Merabol. Dis., 6(1983) 173-182.

26 Ransom, B.R., Bullock, P.N. and Nelson, P.G., Mouse spinal cord in cell culture III Neuronal chemosensitivity and its relationship to synaptic artivity, $J$ Neurophystol., 40 (1977) 1163-1177.

27 Ransom, B.R., Neale, S., Henirart, M., Bullosk, P.N. and Nelson, P.G., Mouse spinal cors in cell culture. I. Morphology and intrinsic neuronal elect:ophysiologic properties, $J$. Neurophysiol., 40 (1977) 1132-1 150.

28 Sakiyamá, T., Nakobayashi, H , Kondo, Y., Shımızu, H., Kodama, $S$. and Kitagawa, $T$, Argininemıa: clinıcal course and trial of enzyme replacement therapy, Biomed Thera- peut. (Tokyo), 8 (1982) 907-910 (in Japanese).

29 Schofield, C.N., Leptazol antagonizes the postsynaptic actnons $\gamma$-aminobutyric acid, $\mathrm{Br}$ J. Pharmacol., 63 (1978) 495-502.

30 Skerritt, J.H. and Macdonald, R.L., Benzodiazepıne receptor ligand actions on GABA responses: $\beta$-carbolines, purines, Eur. J. Pharmacol., 101 (1984) 135-141.

31 Snyderman, S.E., Sansaricq, C., Chen, W.J., Norton, P.M. and Phansalkar, S.V., Argininemia, J. Pediatr., 90 (1977) 563.

32 Snyderman, S.E., Sansaricq, C., Norton, P.M. and Goldstem, F., Arginınemia treated from birth, $J$. Pediatr, (1979) 61-63.

33 Tallman, J.F., Paul, S.M., Skolnick, P. and Gallager, D.W , Receptors of the age of anxiety: pharmacology of the benzodiazepines, Science, 207 (1980) 274-281.

34 Terheggen, H.G., Schwenk, A., Lowenthal, A., Van Sande, M. and Colombo, J.P., Argininemı with argınase deficiency, Lancet, 2 (1969) 748-749.

35 Terheggen, H.G., Schwenk, A., Lowenthal, A., Van Sande, M. and Colombo, J.P., Hyperargininamia mit arginase Defekt. Eıne neue familiare Stoffwechselstörung I Klinische Befunde, Z Kinderhellk, 107 (1970) 298-312.

36 Terhegs̄en, H.G , Sciliwenk, A., Lowentlıal, A, Van Sande, $M$ and Colombo, J.P , Hyperargının ımıa mit Arginase Defekt Eine neue familıare Stofwechselstorung. II Biochemische Untersuchungen, $Z$ Kinderhellk., 107 (1970) 313-323.

37 Terheggen, H.G., Lowenthal, A., Lavinha, F and Colomba, J,P., Familial hyperargininemia, Arch. Dis. Child, 50 (1975) 57-62.

38 Yoshino, M., Kubota, K., Yoshıda, I , Murakani, I and Yamashito, F., Argıninemı: report of a new case and mechanısms of orotic acidurıa and hyperammonemı In A. Lowenthal, $\rightarrow$. Morı and B Marescau (Eds.), Urea Cycle Disease Advances in Expertmental Medicine and Bıology, Vol ijs, Plenum, New York, i982, pp. 121-125. 